\title{
Aggressive interactions between the invasive anemone Anemonia alicemartinae and the native anemone Phymactis papillosa
}

\author{
Antonio Brante ${ }^{1,2, *}$, Rodrigo Riera ${ }^{1}$, Pamela Riquelme $^{1}$ \\ ${ }^{1}$ Departamento de Ecología, Facultad de Ciencias, Universidad Católica de la Santísima Concepción (UCSC), Concepción, Chile \\ ${ }^{2}$ Centro de Investigación en Biodiversidad y Ambientes Sustentables (CIBAS), UCSC, Concepción, Chile
}

\begin{abstract}
The distribution range expansion of species mediated by natural or anthropic mechanisms is one of the main causes of changes in biodiversity patterns. Anemonia alicemartinae is a cryptogenic species found along the coasts of the Southeast Pacific Ocean. This species has expanded its range by $>1900 \mathrm{~km}$ along the Chilean coast throughout the last $50 \mathrm{yr}$. A. alicemartinae cohabits with the native anemone Phymactis papillosa in the low intertidal zone, and given the limited mobility of both species, limited space could encourage aggressive behavior between them. $P$. papillosa shows different color phenotypes, and, as in other anemone species, color is associated with its level of aggressiveness. Here, we evaluated the aggressive behavior of $A$. alicemartinae on 2 color morphotypes of $P$. papillosa. Also, intraspecific agonistic interactions were considered in individuals of $A$. alicemartinae from 2 localities. Four experiments were conducted: (1) individual vs. individual, (2) individual vs. group forming a frontal line, (3) individual vs. group surrounding the individual and (4) group vs. group. Results showed $A$. alicemartinae to be a weak competitor against $P$. papillosa. The cryptogenic species lost more contests with green $P$. papillosa than with the red phenotype. Few aggressive interactions between conspecifics of A. alicemartinae were found. Results suggest that the expansion success of $A$. alicemartinae could be explained by alternative strategies, such as escape behavior, asexual reproduction and high dispersal potential.
\end{abstract}

KEY WORDS: Intraspecific competition · Interspecific competition · Agonistic behavior · Invasion • Chilean coast

\section{INTRODUCTION}

Changes in the spatial distribution of species have become more common in the last century in the context of climate change and increased human activity (e.g. Lima et al. 2007, Lenoir et al. 2008). Species' colonization of new habitats may trigger extensive ecological shifts in the recipient habitat, with important biodiversity, economic and health impacts (Marbuah et al. 2014, Hoffmann \& Broadhurst 2016). Given the increasing importance of this issue, several hypotheses have been suggested to explain the establishment success of species, driven not only by theoreti-

\footnotetext{
${ }^{*}$ Corresponding author: abrante@ucsc.cl
}

cal interest but also in order to establish management policies to prevent species' introduction or reduce their expansion (Kim et al. 2006, Barbier et al. 2013).

It has been suggested that the geographical range of a species is determined by a series of biological and ecological factors (e.g. Castro et al. 2004, Bozinovic et al. 2011). Among these, competitive ability could be one of the main factors determining the establishment success of a species in a recipient community (Pimentel et al. 2000, Brown et al. 2002, Svenning et al. 2014). Most studies evaluating this trait consider invasive species. For example, in an extensively studied group such as terrestrial plants, a

() The authors 2019. Open Access under Creative Commons by Attribution Licence. Use, distribution and reproduction are unrestricted. Authors and original publication must be credited. 
hypothesis regarding high competitive ability states that exotic plants may escape from the control of natural enemies, relocating energy to growth in detriment to defense (Blossey \& Nötzold 1995). However, inconsistent results have been observed in other plant groups (Vilà et al. 2003, Caño et al. 2009, Zheng et al. 2015).

In the marine realm, several studies have explored the role of competitive interactions for invasion success (e.g. Bando 2006, Shinen \& Morgan 2009, Strain \& Johnson 2009, Hart \& Marshall 2012). Food and space availability are the main limiting resources for sessile organisms in the intertidal zone, especially for sessile and sedentary organisms with aggregated distributions (Connell 1961, Harger 1968, Dayton 1971, Menge \& Sutherland 1976). In filter-feeding sedentary species, interspecific competition for sestonic food and attachment substrate has commonly been reported in the intertidal zone (Frechette \& Despland 1999, Shinen et al. 2009). Several studies have suggested that species that have successfully established in a new habitat are better competitors for food and space than native species in marine coastal habitats. For example, on the rocky shore of the NW Pacific coast, the mussel invader Mytilus galloprovincialis is competitively dominant over the native mussels $M$. trossulus and $M$. californianus. The invader outcompetes both native species by physical interference, triggering agglomeration and suffocation and also because it uses resources more efficiently (Shinen \& Morgan 2009).

The marine anemone Anemonia alicemartinae is a cryptic species that has expanded its distribution by $>1900 \mathrm{~km}$ along the coast of the SE Pacific Ocean throughout the past $50 \mathrm{yr}$, with an expansion rate of 38 $\mathrm{km} \mathrm{yr}^{-1}$ (Häussermann \& Försterra 2001). Using molecular analyses, Canales-Aguirre et al. (2015) suggested that the current distribution of this species can be explained by an increase in population size from one small ancestral population, most likely from the south of Peru, with subsequent human-mediated southward transport, probably associated with maritime activities. In combination with maritime transport, previous studies have also suggested that adults of this anemone may show high dispersive potential given their capacity to detach from the substrate, float and drift till they find a new place to settle (López et al. 2013). In addition, asexual reproduction by fission is the main reproductive strategy of $A$. alicemartinae, which may favor a rapid population growth rate (Häussermann \& Försterra 2001). It is interesting to note that $A$. alicemartinae shows the highest aggregation densities in intertidal and subtidal zones where no other anemone species are present (Häussermann \& Försterra 2001). This could suggest that other ecological traits, such as competitive capacity, in combination with other biological characteristics, could explain the expansion success of $A$. alicemartinae.

The native anemone Phymactis papillosa Lesson, 1830 (Häussermann, 2004) cohabits with A. alicemartinae along the intertidal rocky shore of south-central Chile (Häussermann \& Försterra 2001). This species inhabits the intertidal, mostly in sheltered areas and has limited mobility (Rivadeneira \& Oliva 2001). P. papillosa shows 3 phenotypes: red, green and blue. In other anemone, color is related to different aggressiveness levels (e.g. Brace et al. 1979, Watts et al. 2000). For example, red-brown individuals of Actinia equina are more aggressive than green $A$. equina (Brace et al. 1979).

The recent distributional expansion of $A$. alicemartinae along the Chilean coast, the cohabitation of $A$. alicemartinae and $P$. papillosa in the intertidal zone, and the variety of colorations in P. papillosa make both species a suitable model for exploring the role of competition in order to explain species expansion under the framework of invasion ecology. In the present study, we explored the interspecific competitive ability of the cryptogenic anemone $A$. alicemartinae in relation to its aggressive behavior against the red and green phenotypes of the native anemone P. papillosa. We also evaluated intraspecific interactions in the cryptogenic anemone using individuals from 2 different localities in order to account for potential differences in its agonistic behavior, due to the presence of clonal individuals within localities. We specifically addressed the following hypotheses focused on A. alicemartinae: (1) this species demonstrates aggressive behavior against the $2 P$. papillosa phenotypes (red and green); (2) A. alicemartinae shows greater competitive ability when found in aggregations relative to single individuals; (3) A. alicemartinae shows a higher frequency of intraspecific aggressive behavior towards individuals from other locations compared to individuals from the same locality.

\section{MATERIALS AND METHODS}

During the austral winter 2010 (July-August), individuals of the red and green color phenotypes of Phymactis papillosa were collected from the intertidal zone in the locality of Punta Hualpén $\left(36^{\circ} 02^{\prime} \mathrm{S}\right.$, $73^{\circ} 10^{\prime} \mathrm{W}$ ), Biobío region, Chile. To test for interspecific interactions, individuals of Anemonia alicemartinae were collected from the intertidal zone at Lirquén 
$\left(36^{\circ} 43^{\prime} \mathrm{S}, \quad 72^{\circ} 58^{\prime} \mathrm{W}\right)$, Biobío region, Chile. Given that fission is the main reproductive strategy in $A$. alicemartinae (Häussermann \& Försterra 2001), specimens of this species were also collected from the locality of Punta de Parra ( $36^{\circ} 37^{\prime} \mathrm{S}, 72^{\circ} 57^{\prime} \mathrm{W}$ ) from the Biobío region, Chile. In this way, intraspecific aggression behaviors were evaluated in individuals from the same locality (high probability of interactions among clones) and between localities (lesser probability of interactions among clones). The pedal disk size of all specimens ranged in diameter from 3.5 to $4.0 \mathrm{~cm}$. After collection, individuals were transported to the Universidad Católica de la Santísima Concepción's Marine Biological Station Abate Juan Ignacio Molina to run the experiments. In the laboratory, individuals were maintained in aquaria, and ad libitum fed with fresh mussels (Perumitylus purpuratus and Semimytilus algosus). Prior to experiments, all specimens were acclimated for $48 \mathrm{~h}$ in continuous aeration and seawater circulation.

\subsection{Experimental treatments}

Interspecific and intraspecific aggressive behaviors were evaluated in contests between individuals, aggregations and individual vs. aggregation (see Table 1 for treatment combinations). To arrange experiments, each individual was induced to adhere to a $5 \mathrm{~cm}^{2}$ ceramic plate to facilitate manipulation. Anemones attached to plates were acclimated for $24 \mathrm{~h}$ prior to the experiments in tanks with constant aeration and circulation of seawater (salinity $\sim 34 \mathrm{psu}$ and $14 \pm 1^{\circ} \mathrm{C}$ ). For single interactions, single individuals were confronted (Fig. 1a). Aggregations of conspecifics of both species are commonly observed in the field. Therefore, aggregations of individuals were arranged as groups in a line facing the individual (lineal aggregation) and in a circle surrounding the individual (surrounding aggregation) (Table 1, Fig. 1b-d). Five individuals were used in each aggregation, in order to cover the whole perimeter surrounding the focal individual
Table 1. Combination of treatments to evaluate intra- and interspecific aggressive behaviors between the non-native anemone Anemonia alicemartinae (Aa; light red) and the native Phymactis papillosa (Pp) of different color types (G: green, R: darker red). Species were confronted individually and in lineal and surrounding aggregations. Individuals of A. alicemartinae from 2 localities (Lirquén and Punta de Parra; solid and striped, respectively) were considered. Symbols are included to represent each treatment

\begin{tabular}{|c|c|c|c|}
\hline Interspecific interactions & & & Symbol \\
\hline $1 \mathrm{G}-\mathrm{Pp}$ & vs & 1 Aa-Lirquén & \\
\hline \multicolumn{4}{|l|}{$1 \mathrm{R}-\mathrm{Pp}$} \\
\hline $1 \mathrm{G}-\mathrm{Pp}$ - surrounding & vs & 5 Aa-Lirquén & \\
\hline \multicolumn{4}{|l|}{$1 \mathrm{G}-\mathrm{Pp}$ - lineal } \\
\hline \multicolumn{4}{|l|}{$1 \mathrm{R}-\mathrm{Pp}$ - surrounding } \\
\hline \multicolumn{4}{|l|}{$1 \mathrm{R}-\mathrm{Pp}$ - lineal } \\
\hline \multicolumn{4}{|l|}{5 G-Pp - lineal } \\
\hline \multicolumn{4}{|l|}{5 R-Pp - lineal } \\
\hline \multicolumn{4}{|l|}{ Intraspecific interactions } \\
\hline 1 Aa-Punta de Parra & vs & 1 Aa-Lirquén & \\
\hline \multicolumn{4}{|l|}{1 Aa-Lirquén } \\
\hline $\begin{array}{l}1 \text { Aa-Punta de Parra - } \\
\text { surrounding }\end{array}$ & vs & 5 Aa-Lirquén & \\
\hline \multicolumn{4}{|l|}{1 Aa-Punta de Parra - lineal } \\
\hline \multicolumn{4}{|l|}{1 Aa-Lirquén - surrounding } \\
\hline \multicolumn{4}{|l|}{1 Aa-Lirquén - lineal } \\
\hline 5 Aa-Lirquén - lineal & vs & 5 Aa-Lirquén & \\
\hline 5 Aa-Punta de Parra - lineal & & & \\
\hline
\end{tabular}

in surrounding configurations, and in lineal configurations facing the individual. Only A. alicemartinae specimens from Lirquén were used for interspecific experiments, while individuals from Lirquén and Punta de Parra were utilized in intraspecific experiments. For each treatment combination, 20 replicates were run, and all treatments were time-measured to determine the reaction time of individuals in each treatment. The aggressiveness of A. alicemartinae 


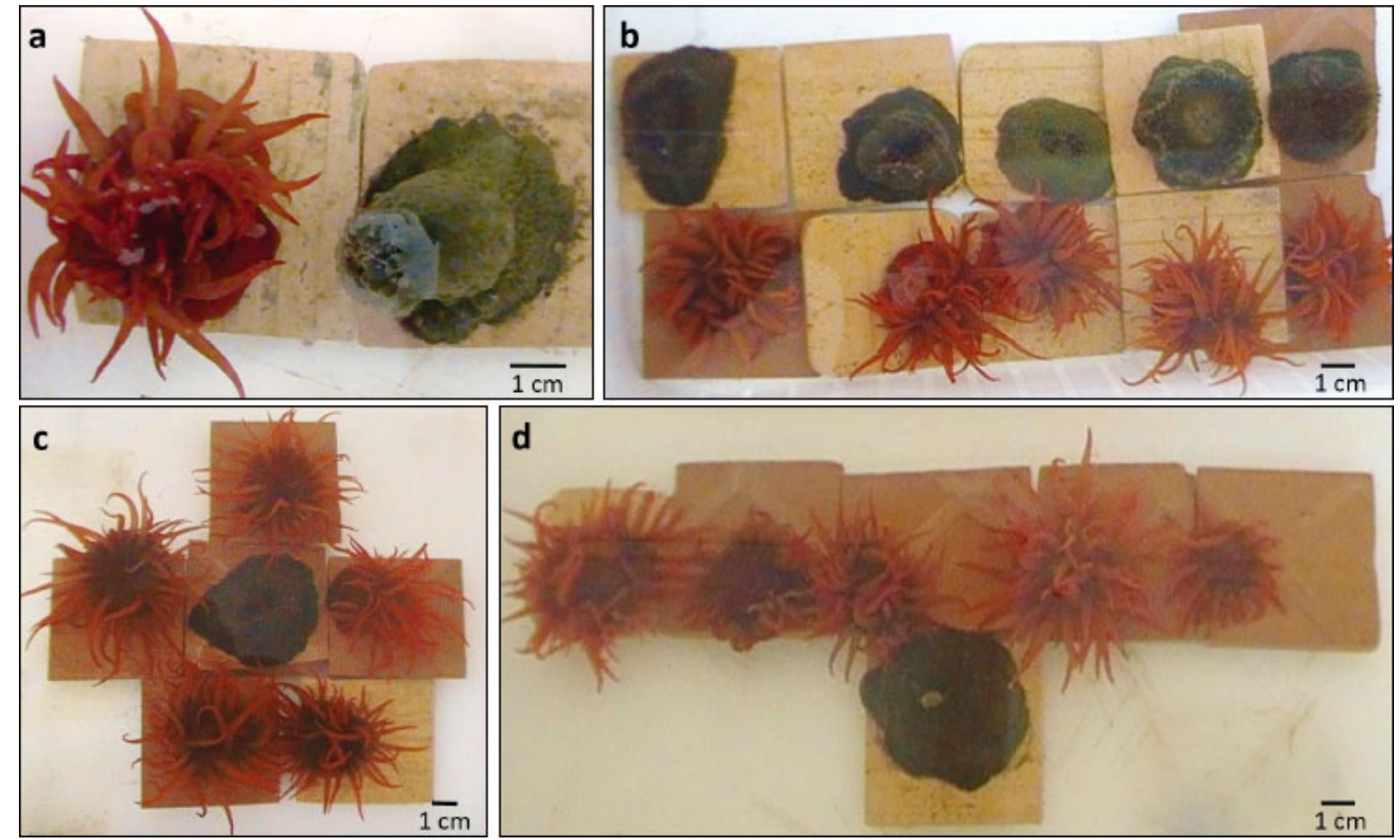

Fig. 1. Species' arrangements in treatments (or contests) designed to evaluate agonistic interactions between the native anemone Phymactis papillosa (green phenotype) and the non-native anemone Anemonia alicemartinae: (a) individual vs. individual,

(b) aggregation vs. aggregation, (c) individual vs. surrounding aggregation, and (d) individual vs. lineal aggregation

was evaluated in each treatment, recording the escape behavior of individuals regardless of the species. Thus, the first individual that detached from the substrate after a direct attack was considered the losing species. A tie was considered when no aggressive behavior was observed between the species (interspecific interaction) or individuals of $A$. alicemartinae from different localities (intraspecific interaction). To avoid potential biases due to fatigue or acrorhagial responses after each contest, individuals were used for experiments only once and then returned to the field.

\subsection{Data analysis}

The results obtained from the treatments were analyzed by chi-squared tests, using a $2 \times 2$ contingency table for each treatment. In all cases, the response variable was the number of contests won (the species that remained on the substrate) by the anemone A. alicemartinae from Lirquén. The expected frequency was calculated considering that none of the evaluated species (A. alicemartinae and $P$. papillosa) would show competitive superiority, i.e. both species would win the same number of contests.
The time (seconds) that individuals took to initiate aggressive behavior was recorded. A 2-way analysis of variance (ANOVA) was conducted, with 2 factors: (1) content arrangement (fixed factor), i.e. individual vs. individual, individual vs. lineal aggregation and individual vs. surrounding aggregation; (2) species considering coloration patterns and location, i.e. Lirquén $A$. alicemartinae vs. green $P$. papillosa, Lirquén A. alicemartinae vs. red $P$. papillosa, Lirquén $A$. alicemartinae vs. Punta de Parra A. alicemartinae, and Lirquén $A$. alicemartinae vs. Lirquén $A$. alicemartinae. Finally, the aggressive behavior of $A$. alicemartinae was recorded by a video camera during the experiments and described afterwards.

\section{RESULTS}

\subsection{Green Phymactis papillosa vs. Anemonia alicemartinae}

Single individuals of $A$. alicemartinae showed significant losses $(80 \%)$ in confrontations against single individuals of green P. papillosa $\left(\chi^{2}=8.89, \mathrm{p}=0.02\right.$; Figs. 2 \& 3A). A similar pattern was observed when lineal aggregations of $A$. alicemartinae interacted 

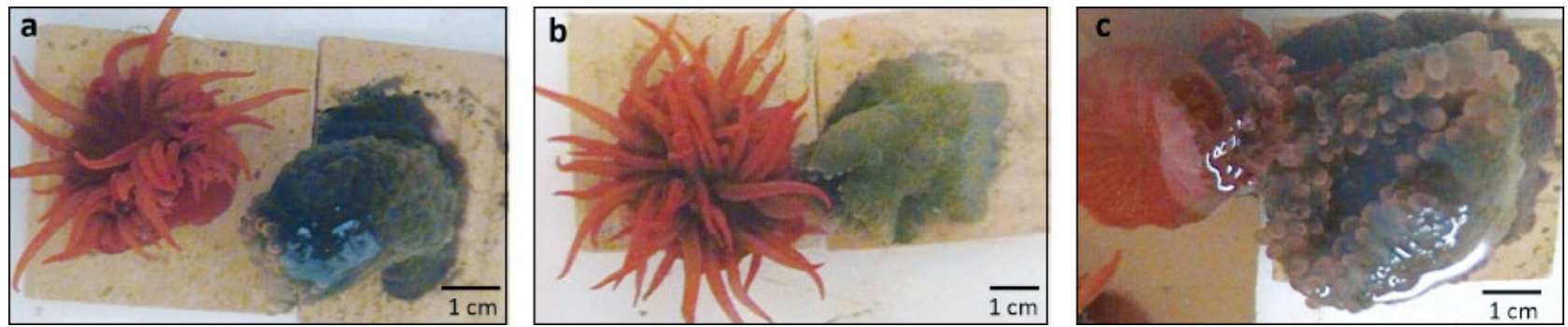

Fig. 2. Sequence showing the aggressive behavior of single individuals of the native anemone Phymactis papillosa's greenphenotype against the non-native anemone Anemonia alicemartinae: (a) P. papillosa directed its tentacles towards the opponent, (b) raised its body, and (c) tilted its body towards A. alicemartinae to stick its tentacles onto its opponent's body, finally retracting in a pulling motion

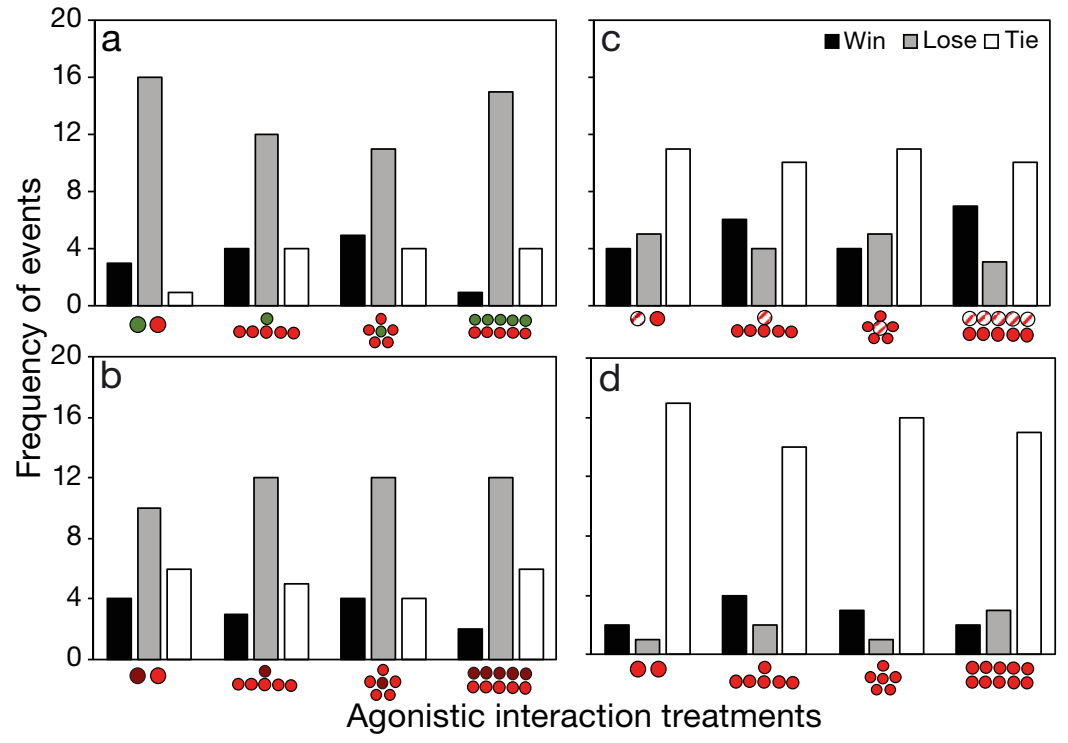

Fig. 3. Results of the agonistic interactions between the non-native anemone Anemonia alicemartinae and the native anemone Phymactis papillosa: interspecific, with (a) green and (b) red $P$. papillosa phenotypes; intraspecific, with A. alicemartinae from (c) both locations and (d) Lirquen only. Symbols on the $x$-axes refer to treatments described in Table 1

with single individuals of green $P$. papillosa $\left(\chi^{2}=\right.$ $4.00, \mathrm{p}=0.04)$, losing $60 \%$ of the total encounters (Figs. 3A \& 4A). When A. alicemartinae aggregates were arranged in the surrounding configuration, no significant trends were observed in interactions with the other species $\left(\chi^{2}=2.25, \mathrm{p}=0.13\right.$; Figs. 3A \& 4B).

When aggregations of both species interacted, $A$. alicemartinae showed significantly lower aggressiveness, losing $75 \%$ of the confrontations $\left(\chi^{2}=\right.$ 12.25, $\mathrm{p}=$ 0.004; Figs. 3A \& 5).

\subsection{Red P. papillosa vs. A. alicemartinae}

No consistent trends were found when single individuals of $A$. alicemartinae confronted single individuals of red P. papillosa $\left(\chi^{2}=2.57, \mathrm{p}=0.11\right.$; Fig. 3B)
However, significant differences were observed when lineal aggregations of $A$. alicemartinae interacted with single individuals of red $P$. papillosa $\left(\chi^{2}=\right.$ $5.40, \mathrm{p}=0.02$ ), with the former losing $60 \%$ of the trials (Fig. 3B). Similar results were also found when $A$. alicemartinae were set in the surrounding configuration to face single individuals of red $P$. papillosa $\left(\chi^{2}=4.00, \mathrm{p}=\right.$ 0.04 ; Fig. 3B). When aggregations of both species interacted, $A$. alicemartinae lost most of the encounters $(60 \%)$ $\left(\chi^{2}=7.14, p=0.007 ;\right.$ Fig. 3B $)$.

\subsection{Intraspecific agonistic behavior in A. alicemartinae}

Intraspecific confrontations between individuals of $A$. alicemartinae from Lirquén (within the locality) and between individuals from the 2 localities finished mostly as ties (Fig. 3C,D). No significant differences were found in any of these contest treatments (Table 2).

\subsection{Response time of the agonistic interaction between both anemone species}

Interaction response time depended upon the identity of the confronting species (A. alicemartinae or $P$. papillosa) and not on the spatial arrangement of the opponents (lineal aggregation, surrounding aggregation or single individuals) (Table 3 ). The a posteriori test showed that the longest response time was observed within conspecific individuals of A. alicemartinae, regardless of their location of origin (mean \pm SD: $34.4 \pm 3.6 \mathrm{~min})$. The shortest response time was 
Table 2. Chi-squared analyses carried out on the different intraspecific interactions between individuals of $A$. alicemartinae from Lirquén and Punta de Parra. Symbols refer to treatments described in Table 1

\begin{tabular}{|c|c|c|}
\hline Intraspecific interactions & $\chi^{2}$ & $\mathrm{P}$ \\
\hline & 0.11 & 0.74 \\
\hline & 0.33 & 0.56 \\
\hline & 0.11 & 0.74 \\
\hline & 0.40 & 0.53 \\
\hline & 1.00 & 0.32 \\
\hline & 0.66 & 0.41 \\
\hline & 0.20 & 0.65 \\
\hline & 1.60 & 0.21 \\
\hline
\end{tabular}

Table 3. A 2-way analysis of variance on the aggressive response times of the non-native Anemonia alicemartinae and the native anemone Phymactis papillosa in different contests. Factors consisted of a spatial arrangement of opponents (individual/individual, individual/lineal aggregations, individual/ surrounding aggregations and lineal aggregations/lineal aggregations). Combination of species treatments were Lirquén $A$. alicemartinae vs. green $P$. papillosa, Lirquén $A$. alicemartinae vs. red $P$. papillosa, Lirquén A. alicemartinae vs. Punta de Parra A. alicemartinae, and Lirquén A. alicemartinae vs. Lirquén $A$. alicemartinae. df: degree of freedom, MS: mean square. Significant differences in bold

\begin{tabular}{|lrrcc|}
\hline Factors & df & \multicolumn{1}{c}{ MS } & $F$ & $\mathrm{p}$ \\
\hline Spatial arrangement (SA) & 3 & 121.6 & 0.79 & 0.50 \\
Species combination (S) & 3 & 1137.5 & 7.38 & $\mathbf{> 0 . 0 0 1}$ \\
SA $\times$ S & 9 & 46.7 & 0.30 & 0.97 \\
Error & 166 & 154.1 & & \\
\hline
\end{tabular}

registered in contests between individuals of $A$. alicemartinae from Lirquén and green phenotype individuals of $P$. papillosa (23.6 $\pm 2.2 \mathrm{~min}$; Table 4$)$.

\subsection{Description of the agonistic behavior between the native and non-native anemones}

Given that aggressiveness was observed mainly in $P$. papillosa, we focused the description of the agonis-
Table 4 . Results of the a posteriori Tukey test for the comparison of the agonistic behavior response times of the nonnative anemone Anemonia alicemartinae and the native anemone Phymactis papillosa in different treatments. T1: Lirquén $A$. alicemartinae vs. green $P$. papillosa, T2: Lirquén $A$. alicemartinae vs. red $P$. papillosa, T3: Lirquén $A$. alicemartinae vs. Punta de Parra A. alicemartinae, T4: Lirquén $A$. alicemartinae vs. Lirquén $A$. alicemartinae. Values in the first row correspond to the mean response times (min). Significant differences in bold $(p<0.05)$

\begin{tabular}{|ccccc|}
\hline & T1 & T & T3 & T4 \\
& 23.62 & 29.7 & 34.4 & 32.6 \\
\hline T1 & & $\mathbf{0 . 0 2 9 6}$ & $\mathbf{0 . 0 0 0 1}$ & $\mathbf{0 . 0 3 1 6}$ \\
T2 & $\mathbf{0 . 0 2 9 6}$ & & 0.2668 & 0.8217 \\
T3 & $\mathbf{0 . 0 0 0 1}$ & 0.2668 & & 0.9585 \\
T4 & $\mathbf{0 . 0 1 6 8}$ & 0.8217 & 0.9585 & \\
\hline
\end{tabular}

tic behaviors on this species. When P. papillosa was first confronted with physical contact, it retracted its tentacles to its mouth. If $A$. alicemartinae made contact again, $P$. papillosa directed its tentacles to the opponent, raising its body and shifting from a circular to an enlarged shape (Fig. 2). P. papillosa then tilted its body towards $A$. alicemartinae and stuck its tentacles onto the opponent's body, then proceeding to retract in a pulling motion. This caused the removal of a few of $A$. alicemartinae's tentacles, and on some occasions, a complete detachment of the body from the surface. This phenomenon caused the displacement of $A$. alicemartinae, which fled from the aggressive behavior of P. papillosa. Lastly, P. papillosa remained in the same place, with fully retracted tentacles, returning to its initial shape and position.

In treatments where single individuals of $P$. papillosa were confronted with a group of $A$. alicemartinae, despite their numerical disadvantage, they won most of the trials. During the frontal line confrontations, $P$. papillosa only attacked its closest $A$. alicemartinae opponent (Fig. 4A). However, when an aggregation of A. alicemartinae surrounded a single individual of $P$. papillosa, P. papillosa responded by attacking all of the individuals in the aggregation, one by one, in order to displace them all (Fig. 4B). In treatments where aggregations of both species were in confrontation, group attacks were not observed; only individuals attacked their closest opponents (Fig. 5).

Lastly, the aggressive behavior observed in individuals of $A$. alicemartinae was quite different than that of P. papillosa. This anemone did not retract its tentacles but kept them open towards the outside. A. alicemartinae made the first contact with its tentacles when confronting the native anemone. Once the contact occurred, A. alicemartinae's escape behavior 

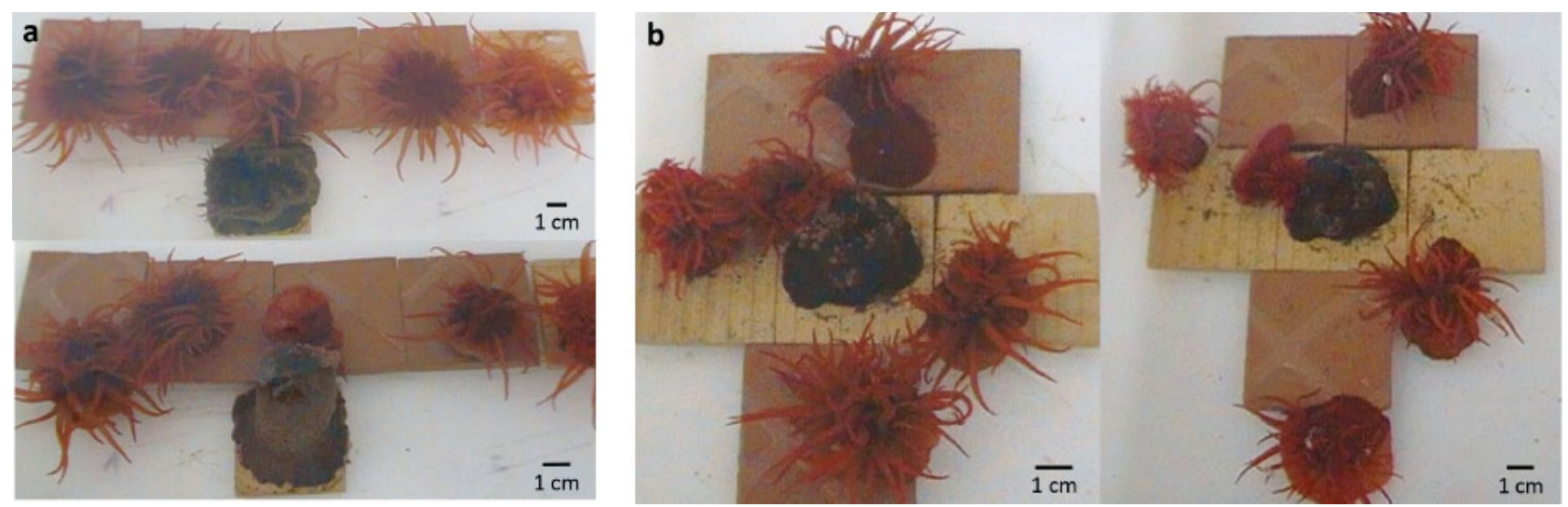

Fig. 4. Sequence showing the aggressive behavior of single individuals of the native anemone Phymactis papillosa's green-phenotype against aggregations of the non-native anemone Anemonia alicemartinae in (a) lineal aggregations and (b) surrounding aggregations
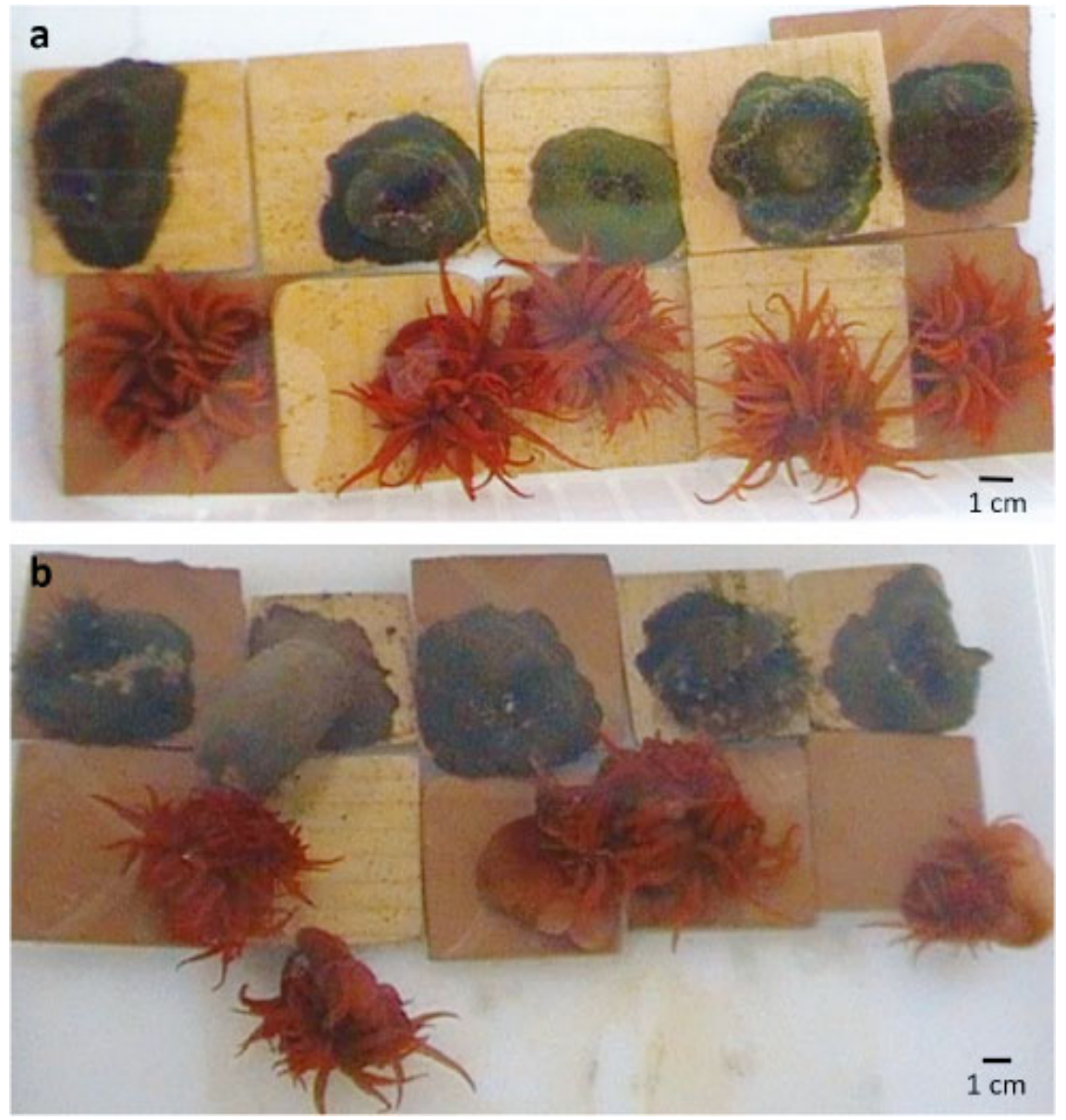

Fig. 5. Sequence showing the aggressive behavior of individuals of the native anemone Phymactis papillosa's green-phenotype against the non-native anemone Anemonia alicemartinae when confronted in lineal aggregations: (a) initial position when both species confronted one another and (b) attack position and dislodgement of A. alicemartinae started; it detached its pedal disk, crawled away with its tentacles, and then inflated its body to finally float away and escape (Fig. 6).

\section{DISCUSSION}

In the present study, we confirmed interspecific agonistic interactions between the native anemone Phymactis papillosa and the cryptogenic anemone Anemonia alicemartinae. These results show that the latter proved to be a weaker competitor in comparison to the native species. A. alicemartinae lost most agonistic encounters, regardless of how many individuals confronted $P$. papillosa. Intraspecific interactions in A. alicemartinae showed that, although relatively higher frequencies of ties were observed between individuals from the same locality compared to contests between conspecifics from different sites, no significant aggressiveness was evidenced among $A$. alicemartinae. The low level of aggressiveness observed in $A$. alicemartinae 


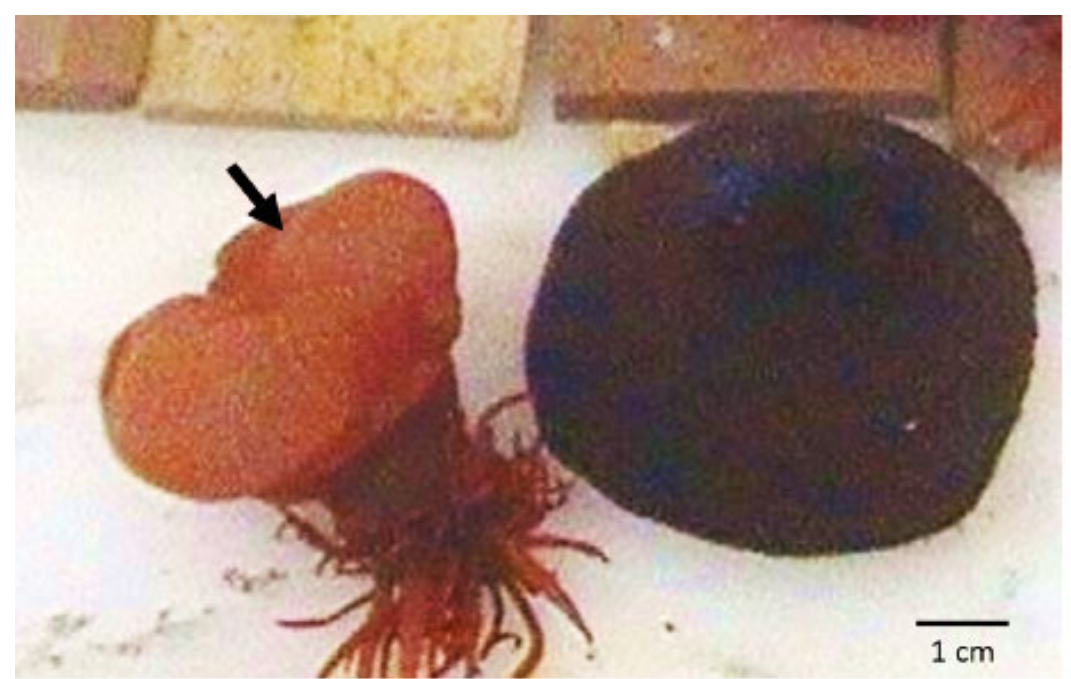

Fig. 6. A. alicemartinae demonstrating its escape behavior from confrontation with the native anemone Phymactis papillosa. Arrow indicates the floating mechanism for dispersal

could be compensated for with other behavioral and biological mechanisms, such as escape behavior and clonal reproduction, which could explain its successful range expansion along the SE Pacific coast.

The 3 key stages of aggressive behavior detailed by Brace (1981) using the anemone P. clematis were observed in the present experiments: (1) initial approach between the 2 species, $A$. alicemartinae and $P$. papillosa, where tentacles of both species tended to enlarge; (2) tentacle extension and flexion, mostly by the native species whose tentacles approached the other species with an apparent nematocyst discharge that triggered a contraction and, in most cases, displacement of $A$. alicemartinae; (3) once the displaced species moved away, the native species returned to its resting position. The aggressive structures of anemone species are acrorhagi (Daly 2003). These structures consist of dense batteries of large cnidocysts used for aggressive behavior. Contact with the acrorhagi may produce an escape response or even death in extreme cases. Individuals of $P$. clematis participating in intraspecific aggression have shown extreme contraction and stretching of the column towards the opponent, resulting in the discharge of nematocysts from the acrorhagi. In this species, the victim has usually been observed to move away and detach from the substratum. In our experiments, attacks of $P$. papillosa did not trigger any necrosis or death of $A$. alicemartinae individuals, at least in a short time period (2 d).

A high variability was observed in aggressive behaviors among the treatments, in terms of frequency and response time. However, as a general pattern, A. alicemartinae was a weak competitor when confronted with P. papillosa and lost more frequently than initially expected. When the 2 color phenotypes of $P$. papillosa were compared, A. alicemartinae showed highly aggressive behavior in the presence of the red phenotype and a faster escape response compared to its reaction to green P. papillosa. Brace (1981), when working with $P$. papillosa, did not differentiate between red and brown colors, observing this combined phenotype to be significantly more aggressive than the green phenotype. However, we herein observed that the green phenotype showed higher competitive success relative to the red phenotype. This discrepancy in respect to Brace (1981) may be explained by potential differences in the aggressiveness level between the red and brown colors of $P$. papillosa, which was not compared in either Brace's work or in the present work. It is clear that additional experiments considering both morphotypes separately are needed.

The total subordination of the cryptogenic anemone $A$. alicemartinae to the native species contrasts with an extensive number of studies in which species that successfully colonize and establish in new habitats overwhelm and displace native species (Molnar et al. 2008). Nonetheless, weak competitors could use alternative strategies to increase their survival and establishment success. A species may occupy habitats where its main competitor is not present to try to avoid direct interactions (Edwards \& Connell 2012). According to previous studies, the anemone A. alicemartinae is rather efficient regarding its escape response, with a high capacity to detach from the substrate, drift in the water column and reattach in a new area and substrate, facilitating dispersion and colonization of more suitable habitats (López et al. 2013). This dispersal strategy has been commonly observed in other anemone species, which may facilitate the colonization of new sites on both small and large spatial scales (Riemann-Zurneck 1998). According to several works, escape behavior in coastal anemones may respond to abiotic stress (e.g. temperature, oxygen, wave strength, desiccation) or biotic factors (e.g. predators, competitors), where detachment and passive migration appear to be part of their life-history strategies (Riemann-Zürneck 1998).

Additionally, the success of $A$. alicemartinae in extending its distributional range may also be ex- 
plained by its high reproductive potential, mainly asexual by fission (Häussermann \& Försterra 2001). This reproductive strategy is rather advantageous during the first stages of expansion, due to founder effect limitations where the encounter of gametes is highly unlikely (Taylor \& Hastings 2005). In the wellknown case of the alga Caulerpa taxifolia invading the Mediterranean Sea, vegetative dissemination could promote its rapid and exponential spread throughout Europe (Sant et al. 1996, Jousson et al. 2000). Among marine invertebrates, the invasive coral species Tubastraea coccinea and T. tagusensis have high frequency of clones in introduced populations along Brazilian coasts, with asexual reproduction dominating in the invasive range and contributing to the invasive success of these species (Capel et al. 2017).

Regarding the non-aggressive interactions of conspecific aggregations of $A$. alicemartinae, this behavior may suggest weak intraspecific competition, regardless of where individuals originate. A plausible explanation could be related to the fact that asexual reproduction is the main strategy in A. alicemartinae. This may produce a high proportion of clonal individuals; therefore, when physical contact occurs, they could histologically recognize each other in terms of compatibility. Former studies using the anemone Actinia equina have shown that the level of aggressiveness is correlated with genetic divergence, showing intra- and interspecific aggression (Turner et al. 2003). Intraspecific aggressiveness in the anemone Anthopleura elegantissima greatly depends on a combination of behavioral and morphological attributes of competing clones (Ayre \& Grosberg 1995). Future genetic studies would help to estimate the proportion of clones within populations of A. alicemartinae.

\section{CONCLUSIONS}

We herein have provided evidence that the cryptogenic anemone Anemonia alicemartinae does not have the capacity to displace competitors with agonistic interactions in order to successfully spread along the Chilean coast. Thus, in species with weak competitive ability, as was observed here when $A$. alicemartinae confronted the native anemone Phymactis papillo$s a$, mechanisms to reduce direct interaction are important in order to increase the probability of establishment. Escape behavior, asexual reproduction and high dispersal potential, all of which have been reported in A. alicemartinae, could explain this species' successful expansion along the Chilean coast. Our findings highlight the importance of understanding the role of interspecific interactions in the context of marine bio-invasion ecology.

Acknowledgements. This work forms part of the DIN 02/ 2009 project. A.B. is grateful for the financial support provided by the FONDECYT grant 1170598.

\section{LITERATURE CITED}

Ayre DJ, Grosberg RK (1995) Aggression, habituation and clonal existence in the sea anemone Anthopleura elegantissima. Am Nat 146:427-453

Bando KJ (2006) The roles of competition and disturbance in a marine invasion. Biol Invas 8:755-763

* Barbier EB, Knowleer D, Gwatipedza J, Reichard SH, Hodges AR (2013) Implementing policies to control invasive plant species. BioScience 63:132-138

Blossey B, Nötzold R (1995) Evolution of increased competitive ability in invasive non-indigenous plants: a hypothesis. J Ecol 83:887-889

Bozinovic F, Calosi P, Spicer JI (2011) Physiological correlates of geographic range in animals. Annu Rev Ecol Evol Syst 42:155-179

Brace RC (1981) Intraspecific aggression in the colour morphs of the anemone Phymacthis clematis from Chile. Mar Biol 64:85-93

*Bace RC, Pavey J, Quicke DLJ (1979) Intraspecific aggression in the colour morphs of the anemone Actinia equina: the 'convention' governing dominance ranking. Anim Behav 27:553-561

Brown B, Mitchell RJ, Graham S (2002) Competition for pollination between an invasive species (purple loosestrife) and a native congener. Ecology 83:2328-2336

Canales-Aguirre CB, Quiñones A, Hernández CE, Neill PE, Brante A (2015) Population genetics of the invasive cryptogenic anemone, Anemonia alicemartinae, along the southeastern Pacific coast. J Sea Res 102:1-9

Caño L, Escarré J, Vrieling K, Sans FX (2009) Palatability to a generalist herbivore, defense and growth of invasive and native Senecio species: testing the evolution of increased competitive ability hypothesis. Oecologia 159:95-106

* Capel KCC, Toonen RJ, Rachid CTC, Creed JC, Kitahara MV, Forsman Z, Zilberberg C (2017) Clone wars: asexual reproduction dominates in the invasive range of Tubastraea spp. (Anthozoa: Scleractinia) in the South-Atlantic Ocean. PeerJ 5:e3873

Castro P, Valladare F, Alonso A (2004) La creciente amenaza de las invasiones biológicas. Rev Cientif Tec Ecol Med Amb 13:61-68

* Connell JH (1961) Effects of competition and predation by Thais lapillus, and other factors on natural populations of the barnacle Balanus balanoides. Ecol Monogr 31: 61-104

Daly M (2003) The anatomy, terminology and homology of acrorhagi and pseudoacrorhagi in sea anemones. Zool Verh Leiden 345:89-101

Dayton PK (1971) Competition, disturbance, and community organization: the provision and subsequent utilization of space in a rocky intertidal community. Ecol Monogr 41: 351-389 
Edwards MS, Connell SD (2012) Competition, a major factor structuring seaweed communities. In: Wiencke C, Bischof K (eds) Seaweed biology, Ecological studies 219. Springer-Verlag, Berlin, Heidelberg, p 135-156

Frechette M, Despland E (1999) Impaired shell gaping and food depletion as mechanisms of asymmetric competition in mussels. Ecoscience 6:1-11

Harger JRE (1968) The role of behavioral traits in influencing the distribution of two species of sea mussel, Mytilus edulis and Mytilus californianus. Veliger 11:45-49

Hart SP, Marshall DJ (2012) Advantages and disadvantages of interference-competitive ability and resource-use efficiency when invading established communities. Oikos 121:396-402

Häussermann V (2004) Redescription of Phymactis papillosa (Lesson, 1830) and Phymanthea pluvia (Drayton in Dana, 1846) (Cnidaria: Anthozoa), two common actiniid sea anemones from the south east Pacific with a discussion of related genera. Zool Meded 78:345-381

Häussermann V, Försterra G (2001) A new species of sea anemone from Chile, Anemonia alicemartinae n. sp. (Cnidaria: Anthozoa). An invader or an indicator for environmental change in shallow water? Org Divers Evol $1: 211-224$

Hoffmann BD, Broadhurst LM (2016) The economic cost of managing invasive species in Australia. NeoBiota 31: $1-18$

Jousson O, Pawlowski J, Zaninetti L, Zechman FW and others (2000) Invasive alga reaches California. Nature 408: $157-158$

Kim CS, Lubowski RN, Lewandrowski J, Eiswerth ME (2006) Prevention or control: optimal government policies for invasive species management. Agric Resour Econ Rev 35:29-40

Lenoir J, Gégout JC, Marquet PA, de Ruffray P, Brisse H (2008) A significant upward shift in plant species optimum elevation during the 20th century. Science 320:1768-1771

Lima FP, Ribeiro PA, Queiroz N, Hawkins SJ, Santos AM (2007) Do distributional shifts of northern and southern species of algae match the warming pattern? Glob Change Biol 13:2592-2604

* López DN, Arancibia PA, Neill PE (2013) Potential dispersal mechanisms of the cryptogenic anemone, Anemonia alicemartinae. Rev Chil Hist Nat 86:369-372

Marbuah G, Gren IM, McKie B (2014) Economics of harmful invasive species: a review. Diversity (Basel) 6:500-523

Menge BA, Sutherland JP (1976) Species diversity gradients: synthesis of the roles of predation, competition, and temporal heterogeneity. Am Nat 110:351-369

Editorial responsibility: Josep-Maria Gili,

Barcelona, Spain
Molnar JL, Gamboa RL, Revenga C, Spalding MD (2008) Assessing the global threat of invasive species to marine biodiversity. Front Ecol Environ 6:485-492

* Pimentel D, Lach DL, Zuniga R, Morrison D (2000) Environmental and economic costs of nonindigenous species in the United States. BioScience 50:53-65

Kiemann-Zürneck K (1998) How sessile are sea anemones? A review of free-living forms in the Actiniaria (Cnidaria: Anthozoa). PSZNI: Mar Ecol 19:247-261

* Rivadeneira M, Oliva E (2001) Patrones asociados a la conducta de desplazamiento local en Phymactis clematis Drayton (Anthozoa: Actiniidae). Rev Chil Hist Nat 74: 855-863

* Sant N, Delgado O, Rodriguez-Prieto C, Ballesteros E (1996) The spreading of the introduced seaweed Caulerpa taxifoha (Vahl) C. Agardh in the Mediterranean Sea: testing the boat transportation hypothesis. Bot Mar 39:427-430

* Shinen JS, Morgan SG (2009) Mechanisms of invasion resistance: competition among intertidal mussels promotes establishment of invasive species and displacement of native species. Mar Ecol Prog Ser 383:187-197

Shinen JL, Morgan SG, Chan AL (2009) Invasion resistance on rocky shores: direct and indirect effects of three native predators on an exotic and a native prey species. Mar Ecol Prog Ser 378:47-54

* Strain EMA, Johnson CR (2009) Competition between an invasive urchin and commercially fished abalone: effect on body condition, reproduction and survivorship. Mar Ecol Prog Ser 377:169-182

* Svenning JC, Gravel D, Holt RD, Schurr FM and others (2014) The influence of interspecific interactions on species range expansion rates. Ecography 37:1198-1209

Taylor CM, Hastings A (2005) Allee effects in biological invasions. Ecol Lett 8:895-908

*Turner VLG, Lynch SM, Paterson L, Loen-Cortes JL, Thorpe JP (2003) Aggression as a function of genetic relatedness in the sea anemone Actinia equina (Anthozoa: Actiniaria). Mar Ecol Prog Ser 247:85-92

*Vilà M, Gómez A, Maron JL (2003) Are alien plants more competitive than their native conspecifics? A test using Hypericum perforatum L. Oecologia 137:211-215

*Watts PC, Allcock AL, Lynch Sm, Thorpe JP (2000) An analysis of the nematocysts of the beadlet anemone Actinia equina and the green sea anemone Actina prasina. J Mar Biol Assoc UK 80:719-724

* Zheng Y, Feng Y, Valiente-Banuet A, Li Y, Liao Z, Zhang J, Chen Y (2015) Are invasive plants more competitive than native conspecifics? Patterns vary with competitors. Sci Rep 5:15622

Submitted: March 27, 2019; Accepted: August 21, 2019 Proofs received from author(s): September 30, 2019 